\title{
Utility of FMS to understand injury incidence in sports: current perspectives
}

This article was published in the following Dove Press journal: Open Access Journal of Sports Medicine

\author{
Meghan Warren' \\ Monica R Lininger ${ }^{1}$ \\ Nicole J Chimera ${ }^{2}$ \\ Craig A Smith ${ }^{1,3}$ \\ 'Department of Physical Therapy \\ and Athletic Training, Northern \\ Arizona University, Flagstaff, AZ, USA; \\ ${ }^{2}$ Department of Athletic Training, \\ Daemen College, Amherst, NY, USA; \\ ${ }^{3}$ Smith Performance Center, Tuscon, \\ AZ, USA
}

\begin{abstract}
The Functional Movement Screen (FMS) is a popular movement screen used by rehabilitation, as well as strength and conditioning, professionals. The FMS, like other movement screens, identifies movement dysfunction in those at risk of, but not currently experiencing, signs or symptoms of a musculoskeletal injury. Seven movement patterns comprise the FMS, which was designed to screen fundamental movement requiring a balance between stability and mobility. The 7 movement patterns are summed to a composite FMS score. For an instrument to have wide applicability and acceptability, there must be high levels of reliability, validity, and accuracy. The FMS is certainly a reliable tool, and can be consistently scored within and between raters. Although the FMS has high face and content validity, the criterion validity (discriminant and convergent) is low. Additionally, the FMS does not appear to be studying a single construct, challenging the use of the summed composite FMS score. The accuracy of the FMS in screening for injury is also suspect, with low sensitivity in almost all studies, although specificity is higher. Finally, within the FMS literature, the concepts of prediction and association are conflated, combined with flawed cohort studies, leading to questions about the efficacy of the FMS to screen for injury. Future research on the use of the FMS, either the composite score or the individual movement patterns, to screen for injury or injury risk in adequately powered, well-designed studies are required to determine if the FMS is appropriate for use as a movement screen.
\end{abstract}

Keywords: movement screen, prediction, sensitivity, athletes

\section{Introduction}

"Movement screen" has become a term used to define screening via movement analysis to identify dysfunction linked to increased risk of musculoskeletal injury or pathology. Screening detects disease or pathology in an individual that is not currently showing signs or symptoms of that disease. ${ }^{1,2}$ Movement screening has the same purpose as any other typical screen - to stratify those at increased injury risk from those not at risk. Stratification allows for targeted intervention in the "at-risk" group with the intent to lower injury occurrence. ${ }^{3}$ For example, Lamontagne et $\mathrm{al}^{4}$ evaluated squat performance in those with and without the diagnosis of hip impingement. Those with hip impingement did not squat as deeply compared with those without hip impingement $(41.5 \% \pm 12.5 \%$ of leg length vs $32.3 \pm 6.8 \%$; $P=0.037)$. From this, a cut-point to stratify those with hip impingement from those without may be developed and used for screening people who participate in activities requiring deep squat (eg, volleyball or powerlifting). A positive test (those that do not squat deep) would lead to further
Correspondence: Meghan Warren Department of Physical Therapy and Athletic Training, Northern Arizona University, PO Box 15105, Flagstaff, AZ 860II, USA

Tel +l 9285235035

Fax + I 9285239289

Email meghan.warren@nau.edu 
testing, possible intervention to prevent injury, and limit future disability from a difficult to treat musculoskeletal pathology that may not initially present as painful or limiting. ${ }^{3}$

Movement screens are developed using different methods including known pathomechanics ${ }^{4}$ and injury mechanisms, ${ }^{5,6}$ sport and fundamental movement requirements, ${ }^{7}$ and expert opinion. ${ }^{8}$ Three broad categories of movement screens have been reported in the literature: jump testing, balance with reaching tests, and movement quality against a standard criterion. Jump testing has been evaluated extensively to determine those at risk for anterior cruciate ligament rupture; ${ }^{9,10}$ the most common test requiring the participant to jump down from a box and land while evaluating the mechanics. ${ }^{10,11}$ Balance with reaching tests, such as the Star Excursion and Y Balance Test (YBT), ${ }^{12}$ have been used to associate poor performance with increased rate of injury in high school ${ }^{13}$ and collegiate athletes. ${ }^{14}$ Movement quality compared against a standard criterion has been used in multiple component assessment tools, ${ }^{7}$ including tasks such as squatting, balance, lunge, push-up, and arm movement. These include the foundation matrix,,$^{15}$ batteries of different movements, ${ }^{16}$ and the movement competency screen. ${ }^{7}$ Perhaps the most wellknown of these type of movement screens, ${ }^{7}$ the Functional Movement Screen ${ }^{\mathrm{TM}}$ (FMS), is the focus of this manuscript. The intent of this manuscript was not to thoroughly review all of the literature on the FMS; several excellent meta-analyses cover measurement aspects of the FMS in detail. ${ }^{17-20}$ Rather the purpose of this manuscript was to review measurement and psychometric indices of the FMS to assist researchers and clinicians with the interpretation of the evidence on FMS.

\section{What is FMS?}

The FMS is a commonly studied and used movement screen to assess injury risk in athletic and nonathletic populations. The FMS was designed to screen performance with fundamental movements, requiring a balance between stability and mobility while moving through a proximal to distal sequence. ${ }^{8,21}$ Seven individual movement patterns comprise the FMS, including deep squat, hurdle step, in-line lunge, shoulder mobility, active straight leg raise, trunk stability push-up, and rotatory stability. Each movement pattern is qualitatively assessed by a rater, and scored 3-0 based on degree of compensatory movements required to complete the movement or the presence of pain ( $3=$ ability to correctly complete the movement pattern without any predefined compensations; $2=$ performing the movement with any one of the movement pattern-specific compensations; $1=$ inability to perform the movement pattern; and $0=$ presence of pain during any portion of the movement pattern). ${ }^{8}$ The scores for the individual movement patterns are than summed to determine the overall composite FMS score.

The FMS is well represented in published literature. PubMed and CINAHL searches (["functional movement screen" or FMS] and injury) were conducted for all papers from January 01, 2006 to February 02, 2018 (limited to English language and human studies), in addition to handsearching reference lists, and resulted in 118 primary (eg, prospective cohort study, experimental trials) and secondary studies (eg, meta-analysis, critically appraised topic). The year 2006 was selected as the beginning of the search as that is when the first papers that described the FMS were published. ${ }^{8,21}$ The research questions the authors posed in these papers covered a wide range, including normative values, ${ }^{22-32}$ differences in scores by several characteristics (eg, sex,,$^{22,33-35}$ body composition, ${ }^{36}$ skill level, ${ }^{37,38}$ reliability and validity, as well as prediction and association with injury). The FMS has been studied in diverse samples, from middle school student ${ }^{22}$ to middle-aged people, ${ }^{23}$ from professional athletes ${ }^{39}$ to military personnel ${ }^{40}$ to civil servants ${ }^{24}$ (eg, police and firefighters). Most of the primary (ie, no systematic reviews/meta-analyses) studies have been conducted using samples of collegiate/university athletes $(n=22),{ }^{37,38,41-60}$ military personnel $(n=13),{ }^{26,40,61-71}$ or physically active people $(n=14) .22,25,27-32,72-77$ FMS studies have been conducted in 16 countries, with the majority conducted in the United States (over 60\%), but also in Europe (eg, Hungary, ${ }^{78}$ Ireland, ${ }^{27}$ Sweden $^{30}$ ), Africa (eg, South Africa ${ }^{72}$ ),

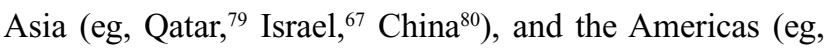
Brazil, ${ }^{29}$ Canada, $^{23}$ and Australia $\left.{ }^{24}\right)$.

The FMS is also a popular movement screening tool that is utilized frequently in clinical settings. Although this is difficult to quantify empirically, FMS is part of the initial screening for the National Hockey League, ${ }^{81}$ national sport clubs internationally (eg, Polish National Handball team), ${ }^{82}$ and physical therapy and athletic performance clinics in the US and worldwide. ${ }^{82,83}$ Through www. functionalmovement. com (distributor of FMS), 22 training courses for FMS were offered in April 2018 around the world, ${ }^{84}$ in addition to online certification courses.

Several studies have established normative values for the summed composite FMS score in a variety of samples (Table 1). ${ }^{23-32}$ The average (mean or median) of the composite FMS score ranged between 13 and 16 . Of these 11 studies, 5 also assessed normative values for the individual movement patterns, but caution is warranted with interpretation. Two of the studies reported mean and SD values for each movement pattern, ${ }^{29,32}$ despite an ordinal level of measurement. This cal- 
Table I Normative values of the FMS

\begin{tabular}{|c|c|c|c|c|c|c|c|c|}
\hline \multirow{2}{*}{$\begin{array}{l}\text { Study } \\
\text { Abraham et al }{ }^{22}\end{array}$} & \multirow{2}{*}{$\begin{array}{l}\text { Sample } \\
\text { size } \\
1,005\end{array}$} & \multirow{2}{*}{$\begin{array}{l}\text { Sample } \\
\text { description }\end{array}$} & \multirow{2}{*}{$\begin{array}{l}\text { Age: mean } \pm \text { SD } \\
\text { or range (years) } \\
10-17\end{array}$} & \multirow{2}{*}{$\begin{array}{l}\text { FMS score: } \\
\text { mean } \pm \text { SD } \\
\text { All: } 14.6 \pm 2.5\end{array}$} & \multicolumn{4}{|c|}{ Movement pattern scores } \\
\hline & & & & & & I (\%) & $2(\%)$ & $3(\%)$ \\
\hline & & & & $\delta: 14.9 \pm 2.6$ & DS & 3.2 & 55.7 & $4 I .4$ \\
\hline & & & & o: $14.2 \pm 2.2$ & $\mathrm{HS}$ & 14.6 & 66.7 & 18.7 \\
\hline & & & & & ILL & 21.8 & 54.6 & 23.6 \\
\hline & & & & & SM & 2.7 & 36.8 & 60.5 \\
\hline & & & & & SLR & 16.2 & 69.6 & 14.2 \\
\hline & & & & & PU & 36.0 & 50.9 & 13.0 \\
\hline & & & & & RS & 25.3 & 57.4 & 17.3 \\
\hline \multirow[t]{2}{*}{ Bardenett et $\mathrm{al}^{25}$} & 167 & High school athletes & $13-18$ & $0: 13.0$ & & & & \\
\hline & & & & +13.1 & & & & \\
\hline \multirow[t]{2}{*}{ Smith et a ${ }^{31}$} & 94 & High school male & $15.5 \pm 1.2$ & Median (range) I6 & & & & \\
\hline & & athletes & & $(9-21)$ & & & & \\
\hline \multirow[t]{7}{*}{ Marques et $\mathrm{al}^{29}$} & 103 & Elite soccer players & $14-20$ & $13.0 \pm 1.6$ & DS & $1.6 \pm 0.6$ & & \\
\hline & & & & & $\mathrm{HS}$ & $2.0 \pm 0.2$ & & \\
\hline & & & & & ILL & $2.0 \pm 0.3$ & & \\
\hline & & & & & SM & $2.3 \pm 1.0$ & & \\
\hline & & & & & SLR & $2.1 \pm 0.7$ & & \\
\hline & & & & & PU & $1.6 \pm 0.8$ & & \\
\hline & & & & & RS & $1.5 \pm 0.5$ & & \\
\hline \multirow[t]{8}{*}{ Agresta et a $\left.\right|^{32}$} & 45 & Healthy distance & $22-54$ & $0: 13.1 \pm 1.7$ & & Male & Female & \\
\hline & & runners & & o: $13.3 \pm 1.9$ & DS & $2.0 \pm 0.5$ & $1.7 \pm 0.5$ & \\
\hline & & & & & HS & $2.0 \pm 0.5$ & $1.7 \pm 0.6$ & \\
\hline & & & & & ILL & $2.1 \pm 0.5$ & $2.3 \pm 0.7$ & \\
\hline & & & & & SM & $1.7 \pm 1.0$ & $2.3 \pm 0.7$ & \\
\hline & & & & & SLR & $1.8 \pm 0.6$ & $2.5 \pm 0.6$ & \\
\hline & & & & & PU & $2.3 \pm 0.7$ & $1.4 \pm 0.5$ & \\
\hline & & & & & RS & $1.5 \pm 0.5$ & $1.7 \pm 0.4$ & \\
\hline \multirow[t]{3}{*}{ Loudon et $\mathrm{a}^{28}$} & 43 & Running athletes & $3: 39.3 \pm 12.8$ & All: $15.4 \pm 2.4$ & & & & \\
\hline & & & o: $33.5 \pm 8.7$ & $3: 15.0 \pm 2.5$ & & & & \\
\hline & & & & o: $16.2 \pm 2.5$ & & & & \\
\hline \multirow[t]{2}{*}{ Fox et $\mathrm{al}^{27}$} & 62 & Male Gaelic field & $22.2 \pm 3.0$ & $15.5 \pm 1.5$ & & & & \\
\hline & & sport athletes & & & & & & \\
\hline \multirow[t]{3}{*}{ Schneiders et a $\mathrm{a}^{30}$} & 209 & Active population & $21.9 \pm 3.7$ & All: $15.7 \pm 1.9$ & & & & \\
\hline & & & $18-40$ & $8: 15.8 \pm 1.8$ & & & & \\
\hline & & & & q: $15.6 \pm 2.0$ & & & & \\
\hline \multirow[t]{3}{*}{ de la Motte et al ${ }^{26}$} & $\mathrm{I}, 037$ & Military applicants & : $: 20.8 \pm 3.0$ & All: $14.7 \pm 1.8$ & & & & \\
\hline & & & $+: 20.9 \pm 3.2$ & $3: 14.8 \pm 1.8$ & & & & \\
\hline & & & & q: $14.4 \pm 1.8$ & & & & \\
\hline \multirow[t]{2}{*}{ Orr et $\mathrm{al}^{24}$} & $|, 5| 2$ & Australian state & : $: 31.3 \pm 8.4$ & : $14.8 \pm 2.6$ & & & & \\
\hline & & police force & $: 28.0 \pm 8.0$ & OP: $15.2 \pm 2.4$ & & & & \\
\hline Perry and Koehle ${ }^{23}$ & 622 & Middle-aged adults & $50.9 \pm 10.8$ & $14.1 \pm 2.9$ & & & & \\
\hline
\end{tabular}

Abbreviations: FMS, Functional Movement Screen; $\delta$, male; + , female; DS, deep squat; HS, hurdle step; ILL, in-line lunge; SM, shoulder mobility; SLR, active straight leg raise; PU, trunk stability push-up; RS, rotatory stability.

culation is potentially problematic because ordinal variables do not have the same properties as interval and ratio levels of measurement; median would be the appropriate measure of central tendency with variability expressed as interquartile range for ordinal variables. Two studies included graphs with the distribution of the movement pattern scores, ${ }^{29,30}$ and 1 listed the percent of scores for each movement pattern. ${ }^{22}$ Although several studies have been conducted reporting normative values, many of these studies are small (ie, only 4 with samples over 500 people $)^{22-26}$ and were conducted in groups for which there are fewer studies about injury association/prediction (except for military). Therefore, establishing population-based norms in the athletic population is still an area that requires future study to better understand the FMS.

\section{Measurement properties for instruments}

A screening tool that is useful in research as well as clinical settings must be both reliable and valid. Researchers have often referred to reliability by different terms such 
as agreement, replication, consistency. However, from a purely psychometric perspective, reliability is the degree to which the measurement is free from error. ${ }^{85}$ The measurement is the dependent or outcome variable that is collected. Error can be from 2 difference sources: systematic change (bias) and random error. Systematic error is when the scores change in a similar orientation between repeated measures. ${ }^{85}$ Random error is from mechanical, biological, or protocol differences that are unpredictable. ${ }^{85}$ Reliability can be estimated over time (test-retest), for internal consistency (interrater, Cronbach $\alpha$ ), and for equivalence (alternative forms).

Validity is the degree to which the instrument measures the construct intended. ${ }^{86}$ While there are many forms of construct validity (Figure 1), this manuscript will focus on face and content (translation validity) along with convergent and discriminant (criterion validity). Translation validity centers on the true meaning of the construct (face and content validity), whereas criterion is the degree of relationship (association or prediction) between the tool and an external source (convergent and discriminant validity).

Accuracy (validity) can be calculated in diagnostic studies using sensitivity and specificity. As a review, sensitivity is the ability of a tool to correctly identify an individual when he/she truly has the condition. Specificity is the ability of a test to correctly identify those who do not have the condition of interest. It is important to understand that a reliable instrument is not necessarily a valid tool. An instrument may come to the same result repeatedly, but that result may not be accurate. Therefore, reliability is a necessary but not sufficient condition for validity. ${ }^{87}$

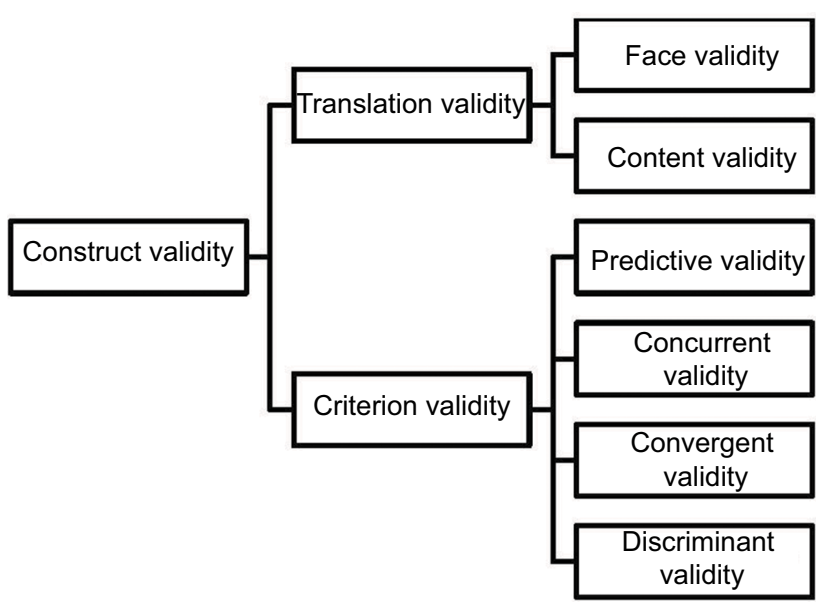

Figure I Types of construct validity.

\section{Reliability}

Seventeen studies have been published that have assessed the reliability of the FMS. ${ }^{16-18,30,41,61,88-97}$ Of these, 1 is a systematic review published in $2016^{97}$ and 2 are systematic reviews with meta-analyses, published in $2016^{17}$ and $2017 .{ }^{18}$ These studies have been conducted in experienced and nonexperienced raters, using physical therapists, athletic trainers, strength and conditioning coaches, and undergraduate and graduate students as raters. These studies have assessed real time as well as video recordings of the FMS performance. Overall, these studies conclude the FMS can be scored consistently, both within (intra-rater) and between (interrater) scorers. In our opinion, the research question of the reliability of the FMS has been thoroughly answered, and this is an area that requires no future study.

\section{Validity \\ Construct validity}

The scoring for the FMS includes summing each of the individual movement pattern scores to a single composite construct to quantify movement dysfunction. ${ }^{8}$ Although there may be benefit for the ease of interpretation and even though the total score has been used extensively in research, evidence does not appear to support a unidimensional construct, or single summed composite score, for the FMS. ${ }^{62,80,98}$ Four factor analyses ${ }^{42,62,80,98}$ assessed the constructs with FMS. In a 2014 exploratory factor analysis using data from 934 Marine Officer candidates, Kazman et al $^{62}$ failed to identify a unidimensional structure for FMS. Reasons for this proposed to be heterogeneity with the compensations for each individual movement pattern, the inclusion of pain as a specific scoring criterion, and different facets being measured with each individual movement pattern. These results of no evidence of a unidimensional construct were replicated in 2015 using data from 290 elite athletes from Chinese national teams. ${ }^{80} \mathrm{In}$ 2016, 2 factor analyses were completed. Koehle et al ${ }^{98}$ completed exploratory and confirmatory factor analyses using retrospective data from 1,113 individuals. These data resulted in 2 factors, a basic movement factor, with shoulder mobility and active straight leg raise, and a complex movement factor, including deep squat, hurdle step, in-line lunge, and the trunk stability push-up, with rotary stability loaded onto both factors. This 2-factor model was tested in a confirmatory factor analysis including data from 176 division 1 student-athletes. ${ }^{42}$ Support for a 1-factor model was found, but also stated that the 1 factor model performed similarly to the 2-factor model. In summary, 1 out of the 4 factors analyses found support for 
a 1-factor model, or a single summed composite score. One study found that a 2-factor model performed best, with the factors revealed that were similar to the original description of the FMS. ${ }^{99}$ Finally, 2 of the 4 studies could not determine a construct and concluded that each individual movement pattern should be assessed independently.

\section{Translation validity}

\section{Face validity}

A screening tool that has a high level of face validity will measure the construct of interest. This is a subjective assessment of construct validity, but is often reported by researchers. For the FMS, face validity has been demonstrated in 2 ways. As stated before, this is a very popular movement screening instrument with over 20 certification courses in 1 month alone all over the world. Additionally, since 2006, there have been 118 papers published that used the FMS. This wide acceptance of the FMS as a movement screening tool in research and clinically also provides evidence for face validity.

\section{Content validity}

Content validity measures how well an instrument captures all possible facets of a construct. This is normally determined through expert opinion of those in the field of interest. Content validity of the FMS was demonstrated because the developer of the FMS, Gray Cook is a board-certified orthopedic physical therapy clinical specialist. In addition, the initial papers describing the FMS included Lee Burton, who is an athletic trainer, and Barb Hogenboom, who is a board-certified sports physical therapist and athletic trainer. The combined expertise in movement analysis from these authors bolsters the content validity of FMS.

\section{Criterion validity}

The criterion validity of the FMS has been assessed in a single study. Whiteside et al ${ }^{100}$ compared the FMS scoring to prespecified kinematic thresholds for 6 of the 7 FMS movement patterns (shoulder mobility excluded) in 11 collegiate athletes. The participants completed the 6 tests of the FMS while assessed by a rater, as well as a kinematic motion capture system. The rater used the standard 4-level scoring for the FMS, while the kinematic analysis used specific criteria for scoring. For example, in the in-line lunge movement pattern for the FMS, 1 of the criteria for the standard scoring was "dowel contact maintained" 100 during the movement pattern. The kinematic equivalent of this was "range of distance from the top hand origin to $\mathrm{C} 7$ and of distance from bottom hand to sacrum both $<5 \mathrm{~cm}$, across the entire exercise." ${ }^{100, \text { p.926 Poor }}$ agreement was found between the 2 methods. Using the example above, the percent agreement was $50.0 \%$ with a $\kappa$ of 0.20 . Evidence for criterion validity is low, and the authors recommended caution with using the FMS and previously published scoring criteria.

\section{Discriminant validity}

Discriminant validity is the ability of a tool to differentiate between 2 people, for example those in 1 group compared to another. A cut-point score from the composite FMS of 14 was published in the first study that used FMS to better understand the value for identifying athletes at a higher risk of injury. ${ }^{101}$ Although 14 is not used as the cut-point for every study using the FMS, ${ }^{58,59,72}$ it is utilized most often (Table 2). Beach et $\mathrm{al}^{102}$ and Frost et al ${ }^{103}$ compared small samples with high $(>14)$ and low $(<14)$ composite FMS scores with back loading mechanics, and lumbar movement and frontal knee motion. In a sample of $15 \mathrm{high}$ and low scorers, Beach et al ${ }^{102}$ found no association with group and peak low back loading magnitudes with lifting. Frost et a ${ }^{103}$ reported less motion with the high scoring group, but substantial interindividual variability with lumbar flexion, extension, lateral side bending, rotation, and frontal knee motion. The authors further concluded, "current FMS scoring criteria may be insensitive to potentially risky movement ('eg, uncontrolled frontal plane knee motion ${ }^{\text {p. } 325}$ ) behavior." ${ }^{\text {103, } .328}$ Only 1 study found different lower extremity mechanics by the FMS scoring criteria, but only studied 1 movement pattern - the deep squat. ${ }^{104}$ In a sample of 28 individuals, 9 scored 1 on the deep squat, 9 scored 2, and 10 scored 3 . Significantly greater peak ankle dorsiflexion and/or dorsiflexion excursion, knee flexion and sagittal plane knee joint excursion, and hip flexion and sagittal plane hip joint excursion, as well as greater knee and hip extension moments were found in the individuals who scored a 3 compared with those who scored lower. Despite this positive finding, the preponderance of findings does not lend support for discriminant validity of the FMS, although additional study of individual movement patterns is needed.

\section{Convergent validity}

Often thought of as an opposite form of discriminant validity, convergent validity assesses if 2 instruments are measuring the same underlying construct. This is commonly represented with a high correlation between 2 different tools or constructs. Six research articles assessed the relationship between the FMS (or a portion of the test) between the FMS and another assessment tool. ${ }^{43,44,63,73,105-107}$ Teyhen et al ${ }^{63}$ evaluated the 
Table 2 Sensitivity, specificity, and AUC of composite FMS ( $\leq 14$ vs $>14)$ studies for injury

\begin{tabular}{|c|c|c|c|c|c|}
\hline Study & Sample & Injury definition & Sensitivity & Specificity & AUC \\
\hline \multicolumn{6}{|l|}{ Collegiate athletes } \\
\hline Garrison et a $\left.\right|^{49}$ & Multiple sports & Med att $+I$ day time loss & 0.67 & 0.73 & NR \\
\hline Warren et al ${ }^{50}$ & Multiple sports & Med att & 0.54 & 0.46 & 0.48 \\
\hline \multirow[t]{4}{*}{ Dorrel et a a ${ }^{\text {a99 }}$} & Multiple sports & Med att + time loss & Value $(95 \% \mathrm{Cl})$ & Value $(95 \% \mathrm{Cl})$ & Value $(95 \% \mathrm{Cl})$ \\
\hline & & All & $0.61(0.53-0.69)$ & $0.49(0.4 I-0.57)$ & $0.56(0.49-0.63)$ \\
\hline & & Severe (3 week time loss) & $0.65(0.43-0.8 I)$ & $0.45(0.39-0.5 \mathrm{I})$ & $0.53(0.4 I-0.66)$ \\
\hline & & Musculoskeletal & $0.62(0.52-0.70)$ & $0.49(0.4 I-0.57)$ & $0.54(0.47-0.6 I)$ \\
\hline Mokha et $\mathrm{al}^{45}$ & $\begin{array}{l}\text { Male soccer, and female } \\
\text { rowing, soccer, volleyball }\end{array}$ & Med att $+\mathrm{I}$ day time loss & 0.26 & 0.59 & 0.36 \\
\hline \multirow[t]{4}{*}{ Bond et $\mathrm{al}^{44}$} & Male and female basketball & Med att & & & \\
\hline & & All & 0.14 & 0.86 & 0.46 \\
\hline & & I-9 day time loss & 0.17 & 0.87 & 0.49 \\
\hline & & $10+$ day time loss & 0.28 & 0.88 & 0.43 \\
\hline Chorba et $\mathrm{a}^{51}$ & $\begin{array}{l}\text { Female basketball, soccer, } \\
\text { volleyball }\end{array}$ & Med att & 0.58 & 0.74 & NR \\
\hline Hotta et $\mathrm{al}^{47}$ & Male runners & Med att +4 week time loss & 0.73 & 0.46 & 0.65 \\
\hline Clay et $\mathrm{a}^{46}$ & Female rowers & Med att $+I$ day time loss & 0.29 & 0.92 & NR \\
\hline Walbright et al ${ }^{52}$ & $\begin{array}{l}\text { Female basketball and } \\
\text { volleyball }\end{array}$ & Med att $+I$ day time loss & $\begin{array}{l}\text { Movement patterns } \\
0.18-1.00\end{array}$ & $\begin{array}{l}\text { Movement patterns } \\
0-0.88\end{array}$ & $\begin{array}{l}\text { Movement patterns } \\
\text { NR }\end{array}$ \\
\hline \multicolumn{6}{|c|}{ Professional athletes } \\
\hline Kiesel et $\mathrm{al}^{39}$ & American football & 3 weeks injured reserve & 0.54 & 0.91 & NR \\
\hline Kiesel et al ${ }^{110}$ & American football & Time loss & 0.27 & 0.87 & NR \\
\hline $\mathrm{Tee}^{\mathrm{b} 72}$ & Rugby union & $>28$ day time loss & 0.62 & 0.77 & 0.73 \\
\hline \multicolumn{6}{|l|}{ Other athletes } \\
\hline Bardenett et $\mathrm{a}^{25}$ & $\begin{array}{l}\text { High school athletes - } \\
\text { multiple sports }\end{array}$ & Med att $+\mathrm{I}$ day time loss & 0.56 & 0.38 & 0.50 \\
\hline Chalmers et $\mathrm{al}^{48}$ & $\begin{array}{l}\text { Elite Junior Australian } \\
\text { football athletes }\end{array}$ & Med att $+I$ day time loss & 0.65 & 0.36 & 0.51 \\
\hline Duke et $\mathrm{al}^{\mid c 58}$ & $\begin{array}{l}\text { Experienced male rugby } \\
\text { union athletes }\end{array}$ & $\begin{array}{l}\text { Any } \\
\text { First half of the season } \\
\text { Second half of the season }\end{array}$ & $\begin{array}{l}0.54 \\
0.36\end{array}$ & $\begin{array}{l}0.95 \\
0.90\end{array}$ & NR \\
\hline \multicolumn{6}{|l|}{ Military } \\
\hline $\begin{array}{l}\text { Cosio-Lima } \\
\text { et al }{ }^{65}\end{array}$ & $\begin{array}{l}\text { Coast Guard Maritime } \\
\text { Security Response Team } \\
\text { candidates }\end{array}$ & Med att & 0.40 & 0.86 & NR \\
\hline \multirow[t]{3}{*}{$\mathrm{O}^{\prime}$ Connor et a ${ }^{40}$} & Marine officer candidates & Any & 0.45 & 0.78 & 0.53 \\
\hline & & Serious & 0.12 & 0.94 & 0.52 \\
\hline & & Overuse & 0.13 & 0.90 & 0.58 \\
\hline \multirow[t]{2}{*}{ Knapik et al ${ }^{66}$} & Coast Guard recruits & Med att & Men: 0.55 & Men: 0.49 & Men: 0.53 \\
\hline & & & Women: 0.60 & Women: 0.61 & Women: 0.59 \\
\hline Everard et $\mathrm{al}^{64}$ & Military recruits & I day time loss & 0.23 & 0.77 & 0.43 \\
\hline Kodesh et $\mathrm{al}^{67}$ & Female soldiers & 2 day time loss & 0.42 & 0.63 & 0.51 \\
\hline \multirow[t]{3}{*}{ Bushman et al ${ }^{68}$} & Light infantry brigade & Any & 0.33 & 0.82 & 0.60 \\
\hline & combat soldiers & Traumatic & 0.28 & 0.77 & 0.54 \\
\hline & & Overuse & 0.37 & 0.81 & $0.6 \mathrm{I}$ \\
\hline \multirow[t]{4}{*}{ Bushman et al ${ }^{69}$} & Light infantry brigade & & Movement patterns & Movement patterns & Movement patterns \\
\hline & combat soldiers & Any & $0.08-0.22$ & $0.90-0.99$ & $0.52-0.57$ \\
\hline & & Traumatic & $0.02-0.19$ & $0.87-0.98$ & $0.50-0.53$ \\
\hline & & Overuse & $0.03-0.24$ & $0.09-0.99$ & $0.51-0.58$ \\
\hline \multicolumn{6}{|l|}{ Other samples } \\
\hline McGill et al ${ }^{122}$ & Police officers & $\begin{array}{l}\text { Back injury without known } \\
\text { mechanism }\end{array}$ & 0.28 & 0.76 & NR \\
\hline Peate et al ${ }^{123}$ & Firefighters & Any injury & 0.36 & 0.71 & NR \\
\hline Butleret al ${ }^{124}$ & Firefighters & 3 day time loss & 0.84 & 0.62 & NR \\
\hline \multirow[t]{3}{*}{ Shojaedin et $\mathrm{a}^{53}$} & University students & Any injury & 0.51 & 0.83 & NR \\
\hline & & Knee injury & 0.14 & 0.93 & \\
\hline & & Ankle injury & 0.13 & 0.95 & \\
\hline
\end{tabular}

Notes: ${ }^{a}$ Cut-point of $<15$ vs $>15$ used. ${ }^{b}$ Cut-point of $<13$ vs $>13$ used. ${ }^{\text {cC }}$ ut-point of $<14.5$ vs $>14.5$ used.

Abbreviations: AUC, area under the curve; Cl, confidence interval; FMS, Functional Movement Screen; NR, not reported; Med att, medically attended. 
relationship between the FMS and the YBT in active duty service members finding that a better performance on the FMS was associated with a greater anterior reach on the YBT. Bond et $\mathrm{al}^{44}$ and Paszkewicz et $\mathrm{al}^{107}$ compared the FMS to a mobility test. Bond et $\mathrm{al}^{44}$ suggested that while the newly constructed Basketball-Specific Mobility Test and the FMS may be appropriate for detecting musculoskeletal deficiencies, this screen and test do not accurately determine injury risk in basketball players at the collegiate setting. Two systematic reviews have been published containing convergent validity measures. ${ }^{108,109}$ Whittaker et al ${ }^{109}$ proposed that only 4 of the 17 included articles assessed the relationships between risk factors. Finally, McCall et al ${ }^{108}$ reviewed the "Top 3" risk factors, screening tests, and preventative exercises used in premier football (soccer) athletes. The FMS, psychological questionnaires, and isokinetic testing all received a " $D$ " (insufficient evidence to assign a specific recommendation) rating for level of evidence. Due to the limited number of rigorous studies assessing the relationship of the FMS with another instrument, convergent validity is low.

\section{Accuracy}

\section{Sensitivity and specificity}

The FMS has been studied extensively related to how well the test can identify those at a risk for injury. Although most researchers report both sensitivity (true positive rate) and specificity (true negative rate), for the association between FMS composite score and injury, the more important metric is sensitivity. High sensitivity means a high number of true positives relative to the number of false negatives (ie, those at a risk for injury for whom the FMS did not identify them at a risk). High specificity means a high number of true negatives relative to the number of false positives (ie, those identified at a risk of injury by the FMS who in actuality did not get injured). In the case of injury, we want to identify as many people as possible who are at risk of injury to work to minimize that risk with injury prevention efforts. If those who are not at a risk get identified at a risk (false-positive), there may be an overuse of resources (ie, putting people in injury prevention programs they may not need), but missing those at a risk of injury (false negatives) could have more serious consequences.

Overall, the sensitivity of the FMS is low (Table 2). For any medically attended injury, the sensitivity ranged from 0.33 to 0.58 ; when time loss was included in the injury definition, the sensitivity was higher generally, except for 4 studies with very low sensitivity ( 0.26 and 0.29 in 2 studies of collegiate athletes), ${ }^{45,46} 0.27$ in professional football players, ${ }^{110}$ and military recruits. ${ }^{64}$ The specificity was much higher, with $15 / 23$ studies reporting specificity higher than 0.70 . This means there was a low false-positive rate relative to the true negative, and the FMS may more correctly classify people who did not sustain an injury.

\section{Relationship between FMS and injury}

By far, the area of largest study for FMS is in the association/prediction of musculoskeletal injury with some facet of the FMS. This includes the composite score, individual movement patterns, asymmetries in movement patterns, or pain with movement patterns. Since 2007, 39 papers have been published on this topic. In addition, 3 systematic reviews and meta-analyses, ${ }^{18-20} 2$ systematic reviews, ${ }^{108,109}$ and 1 review $^{111}$ have also been published. The most comprehensive systematic review and meta-analysis including 24 studies focusing on the FMS composite score and injury association was published in March 2017; therefore, another comprehensive review of the literature is not needed and readers are referred to Moran et al. ${ }^{20}$ In conclusion, this systematic review stated, "the level of evidence for strength of association between FMS composite score and subsequent injury is not sufficient to support the use of FMS composite score as an injury prediction tool." ${ }^{20}$ It is important to note several things about this systematic review. First, of the 24 studies reviewed, only $25 \%(\mathrm{n}=6)$ received a grade of "good" for quality assessment tool, $8 \%(n=2)$ received a grade of "acceptable," and the remaining 67\% were graded as "low" quality. Additionally, only 3 studies conducted with military/ police samples were sufficiently similar to be combined for meta-analysis. Finally, the assessment of the use of FMS as an "injury prediction tool" was made using odds ratios (ORs), relative risks, positive likelihood ratio, focusing on statistical significance; only in 2 cases was area under the curve (AUC) considered. Since this systematic review and meta-analysis was published, another 9 studies have been published examining the association between the FMS composite score and injury. ${ }^{44,46,58,59,64,65,72,112,113}$ Two of the studies in rugby union players reported a significant association, ${ }^{58,72}$ the other 7 supported the conclusion of Moran et $\mathrm{al}^{20}{ }^{20}$ Tee et $\mathrm{al}^{72}$ found significantly lower FMS composite score in professional rugby union players who had a subsequent injury compared to those who did not sustain an injury. Duke et $\mathrm{al}^{58}$ reported significant OR between FMS composite score $\leq 14$ vs $>14$ and any injury for the first half $(\mathrm{OR}=10.42[95 \%$ confidence interval $\{\mathrm{CI}\}: 1.28-84.75])$ and second half $(\mathrm{OR}=4.97[95 \%$ CI: 1.02-24.19]) of the season. 
To most accurately interpret this literature however, a distinction must be made about prediction and causation. Since 2007, there have been 36 studies published using either the FMS composite score, individual movement patterns, or pain with FMS movement patterns to better understand risk profiles of the sample. Of these 36, 27 use the word "prediction" in the title or purpose statement. Unfortunately, many of these papers present ORs as the effect measure and focus on the statistical performance of that effect measure, as was illustrated above with Moran et al. ${ }^{20}$ A smaller ( $n=9$ studies), but more recent, systematic review and meta-analysis on FMS composite score and injury included a table titled, "Injury Predictive Value Studies." "18 This table only listed OR with 95\% CI and focused the discussion on statistical significance only. OR can provide a measure of association between FMS score and injury, but cannot discriminate between who will and will not have an outcome (ie, injury). ${ }^{114}$

AUC and Akaike Information Criterion are some of the more frequently used metrics for prediction. ${ }^{115,116}$ Of these, Akaike Information Criterion was not used in any of the previously published papers that mentioned prediction. AUC is used to discriminate between 2 disease states (eg, injured or not injured) and is defined as the probability that given 2 participants, one who will develop a disease and the other who will not, the model will assign a higher probability of disease to the former. ${ }^{117}$ AUC is used to estimate the risk of an adverse outcome (eg, injury) based on a risk profile (eg, FMS composite score). The AUC for the studies on FMS composite score and injury is very low (Table 2). For many studies, the AUC is $<0.50$, meaning that those with lower FMS scores may, in fact, have a lower probability for injury. Only 2 studies, Tee et $\mathrm{al}^{72}(\mathrm{AUC}=0.73)$ and Hotta et $\mathrm{al}^{47}$ (AUC $=0.65$ ), may be considered predictive of injury. Additionally, 13 of the studies summarized in Table 2 did not include AUC despite many of them having prediction in the title or purpose statement. Therefore the conclusion from Moran et $\mathrm{al}^{20}$ is correct, but the low predictive ability should be interpreted from sensitivity, specificity, and AUC rather than OR from the previously published studies.

\section{Future directions for the FMS and injury}

Although normative data exists for FMS; population-based normative data in athletic populations is lacking. Given the popularity of the FMS as a movement analysis tool in athletic and physically active populations, greater study is needed on larger sport-specific samples to create normative data sets. To date, the FMS as a single construct has been evaluated; however, the construct and criterion validity for all of the movement patterns has yet to be investigated. Further, asymmetries in movement patterns may be more associated with injury than the FMS composite score, ${ }^{45,48}$ this area deserves additional study in a variety of sport-related populations. Many of the previously published prospective cohort studies with the composite FMS scores have been low quality. ${ }^{20}$ In addition to the items cited in the previous review, ${ }^{20}$ these observational studies have been flawed by unadjusted analyses only with poor statistical methodology, small sample size with no a priori sample size or post hoc power calculations in the absence of nonsignificant results, and no discussion about possible effect modification. Rigorous, adequately powered studies that fully adjust confounding are required to fully understand the association of FMS movement patterns and/ or asymmetries with injury. Prediction studies also require sufficient sample size and control of all other variables that may predict injuries (eg, sex, previous injury, skill level). These studies may be sport-specific or encompass a variety of sports.

Future studies on the clinical applicability of the FMS are also needed. A recent item analysis of the FMS suggested that the FMS can possibly be classified into 2 categories - screening for flexibility and evaluation of motor performance. ${ }^{118}$ We recently demonstrated that FMS composite score and movement patterns were affected by lower extremity range of motion and core function. ${ }^{119}$ While the FMS may identify movement dysfunction, the clinical application and implementation of targeted exercise program progression to improve FMS performance needs additional study to ensure consistency among practitioners. ${ }^{120}$ Additionally, FMS movement patterns may be affected by understanding or knowledge of how to perform the specific movement; thus, the FMS may not accurately represent movement dysfunction. ${ }^{121}$ Future research should discern between actual and implied movement dysfunction when using the FMS as a screening tool; this would provide greater clinical relevance to using the FMS in clinical settings.

\section{Conclusion}

The FMS is a popular movement screening tool that can be consistently scored by raters with varied background and training. The FMS also has good translation validity with low criterion validity and sensitivity. Despite the popularity of FMS to describe injury risk, the concepts of prediction and association are conflated in the literature. There is limited evidence for success in injury prediction; the association with injury is more mixed. Much of the previous work on 
the relationship between FMS and injury is flawed by methodological limitations. Adequately powered, well-designed, prospective cohort studies are required to allow final determination of FMS as a movement screen to identify those are higher risk of injury and need for intervention.

\section{Author contributions}

Dr Warren takes responsibility for the integrity of the information contained in this paper. The study was conceived and designed by all the authors. All authors contributed toward data analysis, drafting and critically revising the paper and agree to be accountable for all aspects of the work.

\section{Disclosure}

The authors report no conflicts of interest in this work.

\section{References}

1. Evans MI, Galen RS, Britt DW. Principles of screening. Semin Perinatol. 2005;29(6):364-366.

2. Grimes DA, Schulz KF. Uses and abuses of screening tests. Lancet 2002;359(9309):881-884.

3. van Mechelen W, Hlobil H, Kemper HC. Incidence, severity, aetiology and prevention of sports injuries. A review of concepts. Sports Med. 1992;14(2):82-99.

4. Lamontagne M, Kennedy MJ, Beaulé PE. The effect of cam FAI on hip and pelvic motion during maximum squat. Clin Orthop Relat Res. 2009;467(3):645-650.

5. Bahr R, Krosshaug T. Understanding injury mechanisms: a key component of preventing injuries in sport. Br J Sports Med. 2005;39(6): 324-329.

6. Myer GD, Brent JL, Ford KR, Hewett TE. Real-time assessment and neuromuscular training feedback techniques to prevent anterior cruciate ligament injury in female athletes. Strength Cond $J$. 2011;33(3):21-35.

7. Bennett H, Davison K, Arnold J, Slattery F, Martin M, Norton K. Multicomponent musculoskeletal movement assessment tools: a systematic review and critical appraisal of their development and applicability to professional practice. J Strength Cond Res. 2017;31(10):2903-2919.

8. Cook G, Burton L, Hoogenboom R. Pre-participation screening: the use of fundamental movements as an assessment of function - part 1 . North Am J Sports Phys Ther. 2006;1(2):62-72.

9. Hewett TE, Myer GD, Ford KR, et al. Biomechanical measures of neuromuscular control and valgus loading of the knee predict anterior cruciate ligament injury risk in female athletes: a prospective study. Am J Sports Med. 2005;33(4):492-501.

10. Myer GD, Ford KR, Hewett TE. New method to identify athletes at high risk of ACL injury using clinic-based measurements and freeware computer analysis. Br J Sports Med. 2011;45(4):238-244.

11. Padua DA, Marshall SW, Boling MC, Thigpen CA, Garrett WE Jr, Beutler AI. The Landing Error Scoring System (LESS) is a valid and reliable clinical assessment tool of jump-landing biomechanics. $\mathrm{Am}$ J Sports Med. 2009;37(10):1996-2002.

12. Gribble PA, Hertel J, Plisky P. Using the star excursion balance test to assess dynamic postural-control deficits and outcomes in lower extremity injury: a literature and systematic review. $J$ Athl Train. 2012;47(3):339-357.

13. Plisky PJ, Rauh MJ, Kaminski TW, Underwood FB. Star excursion balance test as a predictor of lower extremity injury in high school basketball players. J Orthop Sports Phys Ther. 2006;36(12): 911-919.
14. Smith CA, Chimera NJ, Warren M. Association of Y balance test reach asymmetry and injury in division I athletes. Med Sci Sports Exerc. 2015;47(1):136-141.

15. Mischiati CR, Comerford M, Gosford E, et al. Intra and inter-rater reliability of screening for movement impairments: movement control tests from the foundation matrix. $J$ Sports Sci Med. 2015;14(2):427-440.

16. Frohm A, Heijne A, Kowalski J, Svensson P. Myklebust G. A nine-test screening battery for athletes: a reliability study: a nine-test screening battery for athletes. Scand J Med Sci Sports. 2012;22(3):306-315.

17. Cuchna JW, Hoch MC, Hoch JM. The interrater and intrarater reliability of the functional movement screen: a systematic review with meta-analysis. Phys Ther Sport. 2016;19:57-65.

18. Bonazza NA, Smuin D, Onks CA, Silvis ML, Dhawan A. Reliability, validity, and injury predictive value of the Functional Movement Screen: a systematic review and meta-analysis. Am J Sports Med. 2017;45(3):725-732.

19. Dorrel BS, Long T, Shaffer S, Myer GD. Evaluation of the Functional Movement Screen as an injury prediction tool among active adult populations: a systematic review and meta-analysis. Sports Health. 2015;7(6):532-537.

20. Moran RW, Schneiders AG, Mason J, Sullivan SJ. Do functional movement screen (FMS) composite scores predict subsequent injury? A systematic review with meta-analysis. Br J Sports Med. 2017;51(23):1661-1669.

21. Cook G, Burton L, Hoogenboom R. Pre-participation screening: the use of fundamental movements as an assessment of function - part 2. N Am J Sports Phys Ther. 2006;1(3):132-139.

22. Abraham A, Sannasi R, Nair R. Normative values for the Functional Movement Screen in adolescent school aged children. Int J Sports Phys Ther. 2015;10(1):29-36.

23. Perry FT, Koehle MS. Normative data for the Functional Movement Screen in middle-aged adults. J Strength Cond Res. 2013;27(2): 458-462.

24. Orr RM, Pope R, Stierli M, Hinton B. A functional movement screen profile of an Australian state police force: a retrospective cohort study. BMC Musculoskelet Disord. 2016;17(1):296.

25. Bardenett SM, Micca JJ, Denoyelles JT, Miller SD, Jenk DT, Brooks GS. Functional Movement Screen normative values and validity in high school athletes: can the $\mathrm{FMS}^{\mathrm{TM}}$ be used as a predictor of injury? Int J Sports Phys Ther. 2015;10(3):303-308.

26. de La Motte SJ, Gribbin TC, Lisman P, Beutler AI, Deuster P. The interrelationship of common clinical movement screens: establishing population-specific norms in a large cohort of military applicants. $J$ Athl Train. 2016;51(11):897-904.

27. Fox D, O'Malley E, Blake C. Normative data for the Functional Movement Screen in male Gaelic field sports. Phys Ther Sport. 2014;15(3):194-199.

28. Loudon JK, Parkerson-Mitchell AJ, Hildebrand LD, Teague C. Functional Movement Screen scores in a group of running athletes. $J$ Strength Cond Res. 2014;28(4):909-913.

29. Marques VB, Medeiros TM, de Souza Stigger F, Nakamura FY, Baroni BM. The Functional Movement Screen (FMS ${ }^{\mathrm{TM}}$ ) in elite young soccer players between 14 and 20 years: composite score, individualtest scores and asymmetries. Int J Sports Phys Ther. 2017;12(6) 977-985.

30. Schneiders AG, Davidsson A, Hörman E, Sullivan SJ. Functional Movement Screen normative values in a young, active population. Int J Sports Phys Ther. 2011;6(2):75-82.

31. Smith LJ, Creps JR, Bean R, Rodda B, Alsalaheen B. Performance of high school male athletes on the Functional Movement Screen ${ }^{\mathrm{TM}}$. Phys Ther Sport. 2017;27:17-23.

32. Agresta C, Slobodinsky M, Tucker C. Functional Movement Screen ${ }^{\mathrm{TM}}$ - normative values in healthy distance runners. Int J Sports Med. 2014;35(14):1203-1207.

33. Anderson BE, Neumann ML, Huxel Bliven KC. Functional Movement Screen differences between male and female secondary school athletes. J Strength Cond Res. 2015;29(4):1098-1106. 
34. Chimera NJ, Smith CA, Warren M. Injury history, sex, and performance on the Functional Movement Screen and Y balance test. J Athl Train. 2015;50(5):475-485

35. Magyari N, Szakács V, Bartha C, et al. Gender may have an influence on the relationship between Functional Movement Screen scores and gait parameters in elite junior athletes - a pilot study. Physiol Int. 2017;104(3):258-269.

36. Cornell DJ, Gnacinski SL, Zamzow A, Mims J, Ebersole KT. Influence of body mass index on movement efficiency among firefighter recruits. Work. 2016;54(3):679-687.

37. Engquist KD, Smith CA, Chimera NJ, Warren M. Performance comparison of student-athletes and general college students on the Functional Movement Screen and the Y balance test. $J$ Strength Cond Res. 2015;29(8):2296-2303.

38. Parchmann CJ, McBride JM. Relationship between Functional Movement Screen and athletic performance. J Strength Cond Res. 2011;25(12):3378-3384.

39. Kiesel K, Plisky PJ, Voight ML. Can serious injury in professional football be predicted by a preseason Functional Movement Screen? N Am J Sports Phys Ther. 2007;2(3):147-158.

40. O'Connor FG, Deuster PA, Davis J, Pappas CG, Knapik JJ. Functional Movement Screening: predicting injuries in officer candidates. Med Sci Sports Exerc. 2011;43(12):2224-2230.

41. Smith CA, Chimera NJ, Wright NJ, Warren M. Interrater and intrarater reliability of the Functional Movement Screen. J Strength Cond Res. 2013;27(4):982-987.

42. Gnacinski SL, Cornell DJ, Meyer BB, Arvinen-Barrow M, Earl-Boehm JE. Functional Movement Screen factorial validity and measurement invariance across sex among collegiate student-athletes. J Strength Cond Res. 2016;30(12):3388-3395.

43. Armstrong R, Greig M. The Functional Movement Screen and modified Star Excursion Balance Test as predictors of T-test agility performance in university rugby union and netball players. Phys Ther Sport. 2018;31:15-21.

44. Bond CW, Dorman JC, Odney TO, Roggenbuck SJ, Young SW, Munce TA. Evaluation of the Functional Movement Screen and a novel basketball mobility test as an injury prediction tool for collegiate basketball players. J Strength Cond Res. Epub 2017 Apr 15.

45. Mokha M, Sprague PA, Gatens DR. Predicting musculoskeletal injury in National Collegiate Athletic Association division II athletes from asymmetries and individual-test versus composite Functional Movement Screen scores. J Athl Train. 2016;51(4):276-282.

46. Clay H, Mansell J, Tierney R. Association between rowing injuries and the Functional Movement Screen ${ }^{\mathrm{TM}}$ in female collegiate division 1 rowers. Int J Sports Phys Ther. 2016;11(3):345-349.

47. Hotta T, Nishiguchi S, Fukutani N, et al. Functional Movement Screen for predicting running injuries in 18- to 24-year-old competitive male runners. J Strength Cond Res. 2015;29(10):2808-2815.

48. Chalmers S, Fuller JT, Debenedictis TA, et al. Asymmetry during preseason Functional Movement Screen testing is associated with injury during a junior Australian football season. J Sci Med Sport. 2017;20(7):653-657.

49. Garrison M, Westrick R, Johnson MR, Benenson J. Association between the Functional Movement Screen and injury development in college athletes. Int J Sports Phys Ther. 2015;10(1):21-28.

50. Warren M, Smith CA, Chimera NJ. Association of the Functional Movement Screen with injuries in division I athletes. J Sport Rehabil. 2015;24(2):163-170

51. Chorba RS, Chorba DJ, Bouillon LE, Overmyer CA, Landis JA. Use of a functional movement screening tool to determine injury risk in female collegiate athletes. North Am J Sports Phys Ther. 2010;5(2): $47-54$.

52. Walbright PD, Walbright N, Ojha H, Davenport T. Validity of functional screening tests to predict lost-time lower quarter injury in a cohort of female collegiate athletes. Int J Sports Phys Ther. 2017;12(6): 948-959.
53. Shojaedin SS, Letafatkar A, Hadadnezhad M, Dehkhoda MR. Relationship between functional movement screening score and history of injury and identifying the predictive value of the FMS for injury. Int J Inj Contr Saf Promot. 2014;21(4):355-360.

54. Sprague PA, Mokha GM, Gatens DR. Changes in Functional Movement Screen scores over a season in collegiate soccer and volleyball athletes. J Strength Cond Res. 2014;28(11):3155-3163.

55. Wiese BW, Boone JK, Mattacola CG, McKeon PO, Uhl TL. Determination of the Functional Movement Screen to predict musculoskeletal injury in intercollegiate athletics. Athl Train Sports Health Care. 2014;6(4):161-169.

56. Bullock GS, Brookreson N, Knab AM, Butler RJ. Examining fundamental movement competency and closed-chain upper-extremity dynamic balance in swimmers. $J$ Strength Cond Res. 2017;31(6): 1544-1551.

57. McCann RS, Kosik KB, Terada M, Beard MQ, Buskirk GE, Gribble PA. Associations between functional and isolated performance measures in college women's soccer players. J Sport Rehabil. 2017;26(5):376-385.

58. Duke SR, Martin SE, Gaul CA. Preseason Functional Movement Screen predicts risk of time-loss injury in experienced male rugby union athletes. J Strength Cond Res. 2017;31(10):2740-2747.

59. Dorrel B, Long T, Shaffer S, Myer GD. The Functional Movement Screen as a predictor of injury in National Collegiate Athletic Association division II athletes. J Athl Train. 2018;53(1):29-34.

60. Busch AM, Clifton DR, Onate JA, Ramsey VK, Cromartie F. Relationship of preseason movement screens with overuse symptoms in collegiate baseball players Int J Sports Phys Ther. 2017;12(6):960-966.

61. Teyhen DS, Shaffer SW, Lorenson CL, et al. The Functional Movement Screen: a reliability study. J Orthop Sports Phys Ther. 2012;42(6):530-540.

62. Kazman JB, Galecki JM, Lisman P, Deuster PA, O'Connor FG. Factor structure of the Functional Movement Screen in marine officer candidates. J Strength Cond Res. 2014;28(3):672-678.

63. Teyhen DS, Shaffer SW, Lorenson CL, et al. Clinical measures associated with dynamic balance and functional movement. $J$ Strength Cond Res. 2014;28(5):1272-1283.

64. Everard E, Lyons M, Harrison AJ. Examining the association of injury with the Functional Movement Screen and Landing Error Scoring System in military recruits undergoing 16 weeks of introductory fitness training. J Sci Med Sport. 2017;21(6):569-573.

65. Cosio-Lima L, Knapik JJ, Shumway R, et al. Associations between Functional Movement Screening, the Y balance test, and injuries in Coast Guard training. Mil Med. 2016;181(7):643-648.

66. Knapik JJ, Cosio-Lima LM, Reynolds KL, Shumway RS. Efficacy of Functional Movement Screening for predicting injuries in Coast Guard cadets. J Strength Cond Res. 2015;29(5):1157-1162.

67. Kodesh E, Shargal E, Kislev-Cohen R, et al. Examination of the effectiveness of predictors for musculoskeletal injuries in female soldiers. J Sports Sci Med. 2015;14(3):515-521.

68. Bushman TT, Grier TL, Canham-Chervak M, Anderson MK, North WJ, Jones BH. The Functional Movement Screen and injury risk: association and predictive value in active men. Am J Sports Med. 2016;44(2):297-304.

69. Bushman TT, Grier TL, Canham-Chervak MC, Anderson MK, North WJ, Jones BH. Pain on Functional Movement Screen tests and injury risk. J Strength Cond Res. 2015;29(Suppl 11):S65-S70.

70. Lisman P, O'Connor FG, Deuster PA, Knapik JJ. Functional Movement Screen and aerobic fitness predict injuries in military training. Med Sci Sports Exerc. 2013;45(4):636-643.

71. McGee JC, Wilson E, Barela H, Blum S. Physical screening predictors for success in completing Air Force Phase II Air Liaison Officer Aptitude Assessment. Mil Med. 2017;182(S1):281-286.

72. Tee JC, Klingbiel JFG, Collins R, Lambert MI, Coopoo Y. Preseason functional movement screen component tests predict severe contact injuries in professional rugby union players. $J$ Strength Cond Res. 2016;30(11):3194-3203. 
73. Janicki JJ, Switzler CL, Hayes BT, Hicks-Little CA. Correlation between ankle-dorsiflexion and hip-flexion range of motion and the Functional Movement Screen hurdle-step score. J Sport Rehabil. 2017;26(1):35-41.

74. Dossa K, Cashman G, Howitt S, West B, Murray N. Can injury in major junior hockey players be predicted by a pre-season Functional Movement Screen - a prospective cohort study. J Can Chiropr Assoc. 2014;58(4):421-427.

75. Sahijwala N, Thomas AJ, Yardi S. Comparative study to determine potential injury risk between active and inactive adults using the Functional Movement Screen. Indian J Physiother Occup Ther. 2016;10(1):109.

76. Hammes D, Aus der Fünten K, Bizzini M, Meyer T. Injury prediction in veteran football players using the Functional Movement Screen ${ }^{\mathrm{TM}}$ J Sports Sci. 2016;34(14):1371-1379.

77. Glass SM, Ross SE. Modified Functional Movement Screening as a predictor of tactical performance potential in recreationally active adults. Int J Sports Phys Ther. 2015;10(5):612-621.

78. Zalai D, Panics G, Bobak P, Csáki I, Hamar P. Quality of functional movement patterns and injury examination in elite-level male professional football players. Acta Physiol Hung. 2015;102(1): $34-42$.

79. Bakken $\mathrm{A}$, Targett $\mathrm{S}$, Bere $\mathrm{T}$, et al. Interseason variability of a functional movement test, the $9+$ screening battery, in professional male football players. Br J Sports Med. 2017;51(14):1081-1086.

80. Li Y, Wang X, Chen X, Dai B. Exploratory factor analysis of the functional movement screen in elite athletes. $J$ Sports Sci. 2015;33(11):1166-1172.

81. Rowan CP, Kuropkat C, Gumieniak RJ, Gledhill N, Jamnik VK. Integration of the Functional Movement Screen into the National Hockey League Combine. J Strength Cond Res. 2015;29(5):1163-1171.

82. Move2Perform [webpage on the Internet]. Who is using it? Evansville, IN: Move2Perform. Available from: https://www.move2perform.com/ who-is-using-it/. Accessed March 1, 2018.

83. FMS [webpage on the Internet]. Partners FMS. Available from: https://www.functionalmovement.com/home/sitepage?title=Partners. Accessed March 1, 2018.

84. FMS [webpage on the Internet]. Events list FMS. Available from: https://www.functionalmovement.com/events. Accessed March 1, 2018.

85. Atkinson G, Nevill AM. Statistical methods for assessing measurement error (reliability) in variables relevant to sports medicine. Sports Med. 1998;26(4):217-238.

86. Terwee CB, Mokkink LB, van Poppel MNM, Chinapaw MJM, van Mechelen W, de Vet HCW. Qualitative attributes and measurement properties of physical activity questionnaires. Sports Med. 2010;40(7):525-537.

87. Nunnally JC, Bernstein IH. Psychometric Theory. 3rd ed. New York: McGraw-Hill; 1994.

88. Gribble PA, Brigle J, Pietrosimone BG, Pfile KR, Webster KA. Intrarater reliability of the Functional Movement Screen. $J$ Strength Cond Res. 2013;27(4):978-981.

89. Gulgin H, Hoogenboom B. The Functional Movement Screening $(\mathrm{FMS})^{\mathrm{TM}}$ : an inter-rater reliability study between raters of varied experience. Int J Sports Phys Ther. 2014;9(1):14-20.

90. Minick KI, Kiesel KB, Burton L, Taylor A, Plisky P, Butler RJ. Interrater reliability of the Functional Movement Screen. $J$ Strength Cond Res. 2010;24(2):479-486.

91. Onate JA, Dewey T, Kollock RO, et al. Real-time intersession and interrater reliability of the Functional Movement Screen. $J$ Strength Cond Res. 2012;26(2):408-415.

92. Parenteau-G E, Gaudreault N, Chambers S, et al. Functional movement screen test: a reliable screening test for young elite ice hockey players. Phys Ther Sport. 2014;15(3):169-175.

93. Shultz R, Anderson SC, Matheson GO, Marcello B, Besier T. Test-retest and interrater reliability of the Functional Movement Screen. $J$ Athl Train. 2013;48(3):331-336.
94. Butler RJ, Plisky PJ, Kiesel KB. Interrater reliability of videotaped performance on the Functional Movement Screen using the 100-point scoring scale. Athl Train Sports Health Care. 2012;4(3):103-109.

95. Leeder JE, Horsley IG, Herrington LC. The inter-rater reliability of the Functional Movement Screen within an athletic population using untrained raters. J Strength Cond Res. 2016;30(9):2591-2599.

96. Waldron M, Gray A, Worsfold P, Twist C. The reliability of Functional Movement Screening and in-season changes in physical function and performance among elite rugby league players. J Strength Cond Res. 2016;30(4):910-918.

97. Moran RW, Schneiders AG, Major KM, Sullivan SJ. How reliable are Functional Movement Screening scores? A systematic review of rater reliability. Br J Sports Med. 2016;50(9):527-536.

98. Koehle MS, Saffer BY, Sinnen NM, Macinnis MJ. Factor structure and internal validity of the Functional Movement Screen in adults. $J$ Strength Cond Res. 2016;30(2):540-546.

99. Cook G. Movement. Aptos, CA: On Target Publications; 2010.

100. Whiteside D, Deneweth JM, Pohorence MA, et al. Grading the Functional Movement Screen: a comparison of manual (real-time) and objective methods. J Strength Cond Res. 2016;30(4):924-933.

101. Kiesel K, Plisky P, Butler R. Functional movement test scores improve following a standardized off-season intervention program in professional football players. Scand J Med Sci Sports. 2011;21(2):287-292.

102. Beach TAC, Frost DM, Callaghan JP. FMS ${ }^{\mathrm{TM}}$ scores and low-back loading during lifting - whole-body movement screening as an ergonomic tool? Appl Ergon. 2014;45(3):482-489.

103. Frost DM, Beach TAC, Campbell TL, Callaghan JP, McGill SM. An appraisal of the Functional Movement Screen ${ }^{\mathrm{TM}}$ grading criteria - is the composite score sensitive to risky movement behavior? Phys Ther Sport. 2015;16(4):324-330.

104. Butler RJ, Plisky PJ, Southers C, Scoma C, Kiesel KB. Biomechanical analysis of the different classifications of the Functional Movement Screen deep squat test. Sports Biomech. 2010;9(4):270-279.

105. Clifton DR, Harrison BC, Hertel J, Hart JM. Relationship between functional assessments and exercise-related changes during static balance. J Strength Cond Res. 2013;27(4):966-972.

106. Okada T, Huxel KC, Nesser TW. Relationship between core stability, functional movement, and performance. $J$ Strength Cond Res. 2011;25(1):252-261.

107. Paszkewicz JR, McCarty CW, Van Lunen BL. Comparison of functional and static evaluation tools among adolescent athletes. J Strength Cond Res. 2013;27(10):2842-2850.

108. McCall A, Carling C, Nedelec M, et al. Risk factors, testing and preventative strategies for non-contact injuries in professional football: current perceptions and practices of 44 teams from various premier leagues. Br J Sports Med. 2014;48(18):1352-1357.

109. Whittaker JL, Booysen N, de La Motte S, et al. Predicting sport and occupational lower extremity injury risk through movement quality screening: a systematic review. Br J Sports Med. 2017;51(7):580-585.

110. Kiesel KB, Butler RJ, Plisky PJ. Prediction of injury by limited and asymmetrical fundamental movement patterns in American football players. J Sport Rehabil. 2014;23(2):88-94.

111. Kraus K, Schütz E, Taylor WR, Doyscher R. Efficacy of the functional movement screen: a review. Strength Cond Res. 2014;28(12):3571-3584

112. Gribble PA, Terada M, Beard MQ, et al. Prediction of lateral ankle sprains in football players based on clinical tests and body mass index. Am J Sports Med. 2016;44(2):460-467.

113. Martin C, Olivier B, Benjamin N. The Functional Movement Screen in the prediction of injury in adolescent cricket pace bowlers: an observational study. J Sport Rehabil. 2017;26(5):386-395.

114. Pepe MS, Janes H, Longton G, Leisenring W, Newcomb P. Limitations of the odds ratio in gauging the performance of a diagnostic, prognostic, or screening marker. Am J Epidemiol. 2004;159(9):882-890.

115. Hajian-Tilaki K. Receiver operating characteristic (ROC) curve analysis for medical diagnostic test evaluation. Caspian J Intern Med. 2013;4(2):627-635.

116. Shmueli G. To Explain or to predict? Stat Sci. 2010;25(3):289-310. 
117. Pencina MJ, D’Agostino RB Sr, D’Agostino RB Jr, Vasan RS. Evaluating the added predictive ability of a new marker: from area under the ROC curve to reclassification and beyond. Stat Med. 2008;27(2):157-172.

118. Kraus K, Doyscher R, Schütz E. Methodological item analysis of the Functional Movement Screen. Deutsche Zeitschrift für Sportmedizin. 2015;2015(10):263-268.

119. Chimera NJ, Knoeller S, Cooper R, Kothe N, Smith C, Warren M. Prediction of Functional Movement Screen ${ }^{\mathrm{TM}}$ performance from lower extremity range of motion and core tests. Int J Sports Phys Ther. 2017;12(2):173-181.

120. Frost DM, Beach TA, Callaghan JP, McGill SM. Using the Functional Movement Screen ${ }^{\mathrm{TM}}$ to evaluate the effectiveness of training. J Strength Cond Res. 2012;26(6):1620-1630.
121. Frost DM, Beach TA, Callaghan JP, McGill SM. FMS scores change with performers' knowledge of the grading criteria - are general whole-body movement screens capturing "Dysfunction"? J Strength Cond Res. 2015;29(11):3037-3044.

122. McGill S, Frost D, Lam T, Finlay T, Darby K, Cannon J. Can fitness and movement quality prevent back injury in elite task force police officers? A 5-year longitudinal study. Ergonomics. 2015;58(10):1682-1689.

123. Peate WF, Bates G, Lunda K, Francis S, Bellamy K. Core strength: a new model for injury prediction and prevention. J Occup Med Toxicol. 2007;2(1):3.

124. Butler RJ, Contreras M, Burton LC, Plisky PJ, Goode A, Kiesel K. Modifiable risk factors predict injuries in firefighters during training academies. Work. 2013;46(1):11-17.
Open Access Journal of Sports Medicine

\section{Publish your work in this journal}

The Open Access Journal of Sports Medicine is an international, peer-reviewed, open access journal publishing original research, reports, reviews and commentaries on all areas of sports medicine. The journal is included on PubMed. The manuscript management system is completely online and includes a very quick and fair
Dovepress

peer-review system. Visit http://www.dovepress.com/testimonials.php to read real quotes from published authors. 